\title{
UM RECORTE DO ESTADO DA ARTE SOBRE ANÁLISE DE ERROS NO PROCESSO DE ENSINO E APRENDIZAGEM DO CÁLCULO DIFERENCIAL E INTEGRAL
}

\author{
A STAT OF THE ART CUT ABOUT ANALYSIS OF ERRORS IN THE TEACHING \\ AND LEARNING PROCESS OF DIFFERENTIAL AND INTEGRAL
}

\author{
Francisco Sebastião Sumbane ${ }^{1}$ \\ ORCID iD: 0000-0003-0130-2118 \\ Josefina Barrera Kalhil ${ }^{2}$ \\ ORCID iD: 0000-0003-1470-7608
}

\begin{abstract}
RESUMO
As pesquisas de Estado da Arte são imprescindíveis para os pesquisadores que têm interesses em explorar um determinado campo científico de conhecimento, pois fornecem ferramentas que orientam as discussões de futuros resultados das pesquisas e auxiliam o entendimento do que se pretende estudar. Este artigo tem como objetivo mostrar como está o desenvolvimento das pesquisas no campo de análise de erros em cálculo diferencial e integral no processo de ensino e aprendizagem. Procedemos um recorte do estado da arte dos últimos cinco anos, 2014 a 2018, no catálogo de Teses e Dissertações de CAPES e nos Programas de Cursos de Pós-graduação em Educação e Ensino de Ciências e Matemática. Fizemos o levantamento de 17 Dissertações e 4 Teses, dos quais selecionamos cinco Dissertações e três Teses para a leitura, onde descrevemos: tema e foco do estudo, informações sobre a amostra, e os resultados fundamentais da pesquisa.
\end{abstract}

Palavras-chave: Análise de erros. Processo de Ensino e Aprendizagem. Cálculo I.

\begin{abstract}
State of the Art research is essential for researchers who have an interest in exploring a particular scientific field of knowledge, as they provide tools that guide the discussions of future research results and assist in understanding what is intended to be studied. This article aims to show how research is developing in the field of error analysis in differential and integral calculus in the teaching and learning process. We proceeded with a cut of the state of the art of the last five years, 2014 to 2018, in the catalog of Theses and Dissertations of Capes and in the Programs of Postgraduate Courses in Education and Teaching of Sciences and Mathematics. We surveyed 17 Dissertations and 4 Theses, two of which selected five Dissertations and three Theses for reading, where we describe: theme and focus of the study, information about the sample, and the fundamental results of the research.
\end{abstract}

\footnotetext{
${ }^{1}$ Discente do Curso de Mestrado em Educação em Ciências na Amazônia da Universidade do Estado do Amazonas (UEA) e Licenciado em Matemática pela Universidade Eduardo Mondlane (UEM). Professor da Escola Superior de Desenvolvimento Rural (ESUDER), Vilankulos, Inhambane, Moçambique. Endereço para correspondência: Avenida Constantino Nery, 2240, São Geraldo, Manaus, Amazonas, Brasil, CEP: 69050-000. E-mail: ciscosumbana@gmail.com.

${ }^{2}$ Doutora em Ciências Pedagógicas pela Universidade da Havana (2003) e Mestre em Ciências da Educação Superior pela Universidade de Matanzas, Cuba (1998), Professora na Universidade do Estado do Amazonas (UEA) Manaus, Amazonas, Brasil. Endereço para correspondência: Avenida Constantino Nery, 3451, Chapada, Manaus, Amazonas, Brasil, CEP: 69050-001. E-mail: josefinabk@gmail.com.
} 
Keywords: Error analysis. Teaching and Learning Process. Calculus I.

\title{
1. INTRODUÇÃO
}

O Estado da Arte é um estudo que trata das pesquisas realizadas por investigadores com o intuito de fundamentar teoricamente e orientar as discussões dos futuros trabalhos científicos, o que é sustentado por Romanowski e Ens (2006) ao ressaltarem que:

\begin{abstract}
Estados da arte podem significar uma contribuição importante na constituição do campo teórico de uma área de conhecimento, pois procuram identificar os aportes significativos da construção da teoria e prática pedagógica, apontar as restrições sobre o campo em que se move a pesquisa, as suas lacunas de disseminação, identificar experiências inovadoras investigadas que apontem alternativas de solução para os problemas da prática e reconhecer as contribuições da pesquisa na constituição de propostas na área focalizada (p.38)
\end{abstract}

Romanowski e Ens (2006) afirmam ainda que para a realização do Estado da Arte é preciso considerar certos aspectos: a definição dos descritores para direcionar as buscas a serem realizadas, localização de bancos de pesquisas, Teses e Dissertações, catálogos e acervos de bibliotecas, biblioteca eletrônica, coleções de periódicos, levantamento de Teses e Dissertações catalogadas, leitura das publicações com elaboração de síntese preliminar e organização do relatório de síntese.

Fizemos um recorte de cinco (5) anos, de 2014 a 2018, no catálogo de Teses e Dissertações da Coordenação de Aperfeiçoamento de Pessoal de Nível Superior (CAPES) e nos Programas de Cursos de Pós-Graduação em Ensino de Ciências e Matemática. As buscas foram efetuadas com base nas palavras-chave "Erro"; "Cálculo I"; "Limite de funções"; "Análise de erros"; "Continuidade de funções"; "Obstáculos epistemológicos" e "Cálculo e Diferencial". Após análise dos trabalhos, selecionamos aqueles que abordam conteúdos mais relacionados com a nossa pesquisa, e em seguida, procedemos a leitura dos mesmos selecionando: o autor, a temática, ano de publicação, instituição de ensino, e as respetivas contribuições no processo de ensino e aprendizagem.

Para Bachelard (1996) toda a pesquisa é resposta a uma pergunta. Neste trabalho pretendemos responder a seguinte inquietação: De que forma são discutidos os erros conceituais em Cálculo Diferencial e Integral nas pesquisas dos cursos de Pós-graduações em Ensino de Ciências e Matemática.

A escolha deste estudo deriva-se pela pretensão de dar mais subsídios e sustentação à nossa pesquisa do Mestrado Acadêmico em Educação em Ciências na Amazônia, intitulada: 
Análise de Erros em Cálculo I - Um Estudo com os alunos do Curso de Licenciatura em Matemática.

A pesquisa foi desenvolvida com o propósito de evidenciar como está o desenvolvimento das pesquisas na Educação Matemática, no campo de análise de erros em Cálculo Diferencial e Integral. Estruturamos a pesquisa em quatro momentos: Primeiro fizemos uma introdução da pesquisa, segundo elaboramos os pressupostos teóricos e epistemológicos da pesquisa, terceiro momento nos ocupamos na descrição e discussão das Teses e Dissertações selecionadas para a leitura e o último momento descrevemos algumas considerações finais.

\section{REFERÊNCIAL TEÓRICO}

A análise de erros como um campo de estudo de interesse nas pesquisas em Educação Matemática teve o seu início no século XX, e foi influenciado pelos momentos de behaviorismo, processamento da informação e construtivismo.

$\mathrm{Na}$ vida quotidiana, assim como no processo de ensino e aprendizagem, é inevitável abordar questões relacionadas com o acerto e o erro. Na perspectiva de Macedo (2002), o erro no plano de fazer consiste na incapacidade de produzir um resultado esperado, considerando os objetivos propostos a serem alcançados, o que implica o domínio dos meios necessários, porém, nem sempre os procedimentos utilizados são adequados em função dos propósitos desenhados e exigem correções totais ou parciais.

O autor afirma ainda que a construção do conhecimento é feita a través das interações sujeito-objeto, onde nessas trocas, entre ambos, algo sempre é corrigido (feedback negativo) ou mantido (feedback positivo). Nesse panorama, o erro é visto como fator integrante no processo da construção do conhecimento científico, pois, "numa perspectiva construtivista o problema é o da invenção e da descoberta, nos quais erro e acerto são inevitáveis, fazem parte do processo" (MACEDO,2002, p.71).

Para Bachelard (1996, p.14), no progresso científico é inevitável a ocorrência de erros conceituais, pois questiona que "a experiência que não retifica nenhum erro, que é monotonamente verdadeira, sem discussão, para que serve?” Além de corrigir os erros dos alunos, no processo de ensino e aprendizagem, é imprescindível que os professores permitam que esses erros sejam observáveis para os alunos, de modo que reflitam sobre as suas ações.

Popper, na sua obra Conjeturas e Refutações (2018), fez o seguinte questionamento: Como podemos detectar e eliminar o erro? A resposta adequada para a pergunta colocada é 
“criticando as teorias ou suposições dos outros e se nós conseguirmos ensinar a fazê-locriticando as nossas próprias teorias ou suposições” (p. 72).

Macedo (2002) citando Piaget, (1976/1987), afirma que um erro corrigido pode ser mais produtivo do que um êxito imediato, o que é também sustentado por Popper (2018, p. 363) ao dizer que, em "ciência, aprendemos frequentemente com os nossos erros, e é por isso que podemos falar, clara e judiciosamente em fazer progressos nela".

Segundo Pinto (2000), o erro pode ser visto como uma estratégia didática para o professor, a medida em que fornece procedimentos para um planejamento do ensino eficaz e oferece elementos para o professor refletir sobre as suas práticas pedagógicas. A autora, a partir da teoria psicogenética, aborda o erro cometido pelos alunos em três níveis nomeadamente:

- Nível I: O aluno não compreende o erro cometido, substituindo somente o errado pelo acerto no seu caderno sendo que a correção é feita de uma forma mecânica. Nesta fase o aluno necessita do apoio do professor para compreender o processo de correção.

- Nível II: O aluno identifica o erro, faz tentativas de correção, todavia não consegue superar sozinho, porém consegue corrigir com as recomendações dadas pelo professor e também pela ajuda de colegas e dos manuais didáticos.

- Nível III: O erro é observável ao aluno, não precisa de ajuda externa para a superação dos erros e auxilia os colegas, praticamente são erros de distração que se comete.

Rico et al (1998) partindo dos estudos de Brousseau, Davis e Werner (1986) indicou quatro maneiras pelas quais o erro pode ocorrer, a saber:

- Os erros são frequentemente o resultado de grandes concepções inadequadas sobre aspectos fundamentais da matemática;

- Os alunos geralmente têm grandes conceitos errados sobre aspectos fundamentais da matemática;

- Erros também podem ocorrer quando o aluno usa procedimentos imperfeitos e possui concepções inadequadas que não são reconhecidas pelo professor, que podem ser observadas nas trocas de experiências entre o professor- aluno;

- Os alunos, geralmente, inventam seus próprios métodos, não formais, mas altamente originais, para a conclusão das tarefas propostas e a resolução de problemas.

Alguns erros, cometidos pelos alunos na disciplina de Matemática, podem estar relacionados com dados mal utilizados, interpretação incorreta da linguagem, inferências logicamente inválidas, teoremas ou definições deformadas, falta de verificação da solução e erros técnicos (HADAR et al, 2005). 


\section{METODOLOGIA}

Nesta investigação optamos por uma pesquisa bibliográfica, que consistiu no levantamento de Teses e Dissertações, numa demarcação dos cinco anos de 2014 a 2018. A nossa base de dados foi o repositório de CAPES e dos cursos de Pós-graduação em Educação e Ensino de Ciências e Matemática. A busca dos trabalhos foi efetuada com base nas palavras-chave "erro"; "Cálculo I"; "Limite de funções"; "Análise de erros"; "Continuidade de funções”; "Obstáculos epistemológicos" e "Cálculo Diferencial” Em seguida, fizemos a tabulação dos dados das pesquisas e selecionamos as Dissertações e Teses para a leitura devido a aproximação à nossa pesquisa.

\section{ANÁLISES E RESULTADOS}

Trazemos na tabela 1 pesquisas sobre Dissertações e Teses levantadas, onde identificamos: autoria, tema, instituição do ensino e palavras-chave, respetivamente.

\begin{tabular}{|c|c|c|c|}
\hline \multicolumn{4}{|c|}{ DISSERTAÇÕS } \\
\hline $\begin{array}{l}\text { Autoria } \\
\text { Ano }\end{array}$ & Título da pesquisa & Instituição do ensino & Palavras-chaves \\
\hline $\begin{array}{l}\text { Sabrina Londero } \\
\text { da Silva Rossato } \\
\text { (2014) }\end{array}$ & $\begin{array}{l}\text { Análise de erros na divisão } \\
\text { de números decimais por } \\
\text { alunos do } 6^{\circ} \text { ano do ensino } \\
\text { fundamental }\end{array}$ & $\begin{array}{c}\text { Centro } \\
\text { Universitário Franciscano }\end{array}$ & $\begin{array}{l}\text { Divisão de decimais. } \\
\text { Análise de erros. } \\
\text { Aprendizagem } \\
\text { significativa. }\end{array}$ \\
\hline $\begin{array}{l}\text { Renato Rodrigues } \\
\text { dos Santos (2014) }\end{array}$ & $\begin{array}{l}\text { Análise de erros em } \\
\text { questões de Geometria do } \\
\text { ENEM: um estudo com } \\
\text { alunos do Ensino Médio }\end{array}$ & $\begin{array}{l}\text { Universidade Estadual de } \\
\text { Maringá }\end{array}$ & $\begin{array}{l}\text { Análise de erros. } \\
\text { Ensino de Geometria. } \\
\text { ENEM }\end{array}$ \\
\hline $\begin{array}{l}\text { Fabrício } \\
\text { Figueredo } \\
\text { Monção (2015) }\end{array}$ & $\begin{array}{l}\text { Uma leitura dos erros } \\
\text { cometidos por estudantes } \\
\text { na resolução de questões do } \\
\text { cálculo diferencial e } \\
\text { integral }\end{array}$ & $\begin{array}{l}\text { Universidade Estadual do } \\
\text { Sudoeste da Bahia }\end{array}$ & $\begin{array}{l}\text { Análise de Erros; } \\
\text { Cálculo diferencial e } \\
\text { integral; matemática } \\
\text { na Educação Básica. }\end{array}$ \\
\hline
\end{tabular}




John Kennedy
Jerônimo Santos
(2015)
(2015)
A compreensão do

professor sobre os erros

dos alunos em itens

envolvendo expectativas de aprendizagem dos números racionais, nos anos inicias do ensino fundamental
Universidade Federal de Pernambuco
Erros. Números

Racionais. Avaliação da aprendizagem.

Professores.

Expectativas de

Aprendizagem
Análise de erros no cálculo

Maria Josiele de perímetro e área de

Fusiger (2015) figuras planas no ensino médio
Centro

Universitário Franciscano
Área. Análise de

Erros. Ensino Médio
Beatriz Alves da Silva Dalmolin (2015)
A tricotomização entre aritmética, Álgebra e Geometria nos erros apresentados por estudantes da disciplina de Cálculo Diferencial e Integral
Universidade do Sul da Santa Catarina
Tricotomia entre aritmética, geometria e álgebra; erros; Cálculo Diferencial e Integral I; Teoria Histórico-Cultural
Heloisa de Andrade Carvalho (2016)

$\begin{array}{lr}\text { Ana } & \text { Lúcia } \\ \text { Gonçalves de } \\ \text { Andrade de Silva } \\ \text { (2016) }\end{array}$

Raul Francisco da Silva Nascimento (2017)

\begin{tabular}{|c|c|c|c|c|}
\hline 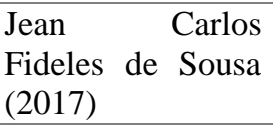 & $\begin{array}{l}\text { Sobre equações e funções } \\
\text { na educação básica, uma } \\
\text { análise de erros }\end{array}$ & $\begin{array}{l}\text { Universidade } \\
\text { Ceará }\end{array}$ & Federal do & $\begin{array}{l}\text { Equação. } \\
\text { Função. } \\
\text { Erros. }\end{array}$ \\
\hline $\begin{array}{l}\text { José } \quad \text { Rogério } \\
\text { Barreto (2017) }\end{array}$ & $\begin{array}{l}\text { Análise de erros cometidos } \\
\text { por alunos do } 6^{\circ} \text { ano na } \\
\text { resolução de problemas } \\
\text { envolvendo operações com }\end{array}$ & $\begin{array}{l}\text { Universidade } \\
\text { Sergipe }\end{array}$ & Federal de & $\begin{array}{l}\text { Operações } \\
\text { frações; Análise de } \\
\text { erros; Resolução de } \\
\text { Problemas }\end{array}$ \\
\hline $\begin{array}{l}\text { Thyago Araujo } \\
\text { Ferreira (2017) }\end{array}$ & $\begin{array}{l}\text { Resolução de problemas de } \\
\text { probabilidade no ensino } \\
\text { médio: Uma análise de } \\
\text { erros em provas da } \\
\text { OBMEP no Maranhão }\end{array}$ & $\begin{array}{l}\text { Universidade } \\
\text { Maranhão }\end{array}$ & Federal de & $\begin{array}{l}\text { Probabilidade; } \\
\text { OBMEP; Análise de } \\
\text { erros }\end{array}$ \\
\hline $\begin{array}{l}\text { Patrícia Cacho do } \\
\text { Nascimento } \\
(2017)\end{array}$ & $\begin{array}{l}\text { Um estudo sobre os erros } \\
\text { dos alunos em cálculo } \\
\text { diferencial e integral I em } \\
\text { um curso de engenharia } \\
\text { civil }\end{array}$ & $\begin{array}{l}\text { Universidade } \\
\text { Sul }\end{array}$ & Cruzeiro do & $\begin{array}{l}\text { Análise de erros, } \\
\text { Cálculo diferencial e } \\
\text { integral, Processo }\end{array}$ \\
\hline
\end{tabular}

A análise dos erros dos alunos em Cálculo I como estratégia de ensino Aprender com os erros: uma estratégia didática no ensino da Matemática em Geometria na segunda série do ensino médio

Análise de erros no processo de resoluções de proporcionalidade
Pontifícia Universidade

Análise de Erros;

Católica do Rio de Janeiro

Universidade Federal do estratégia didática,

Vale do São Francisco aprendizagem

Análise de erros;

Universidade Federal do Matemática;

Oeste do Pará Proporcionalidade

Universidade Federal do Função. Erros.

frações; Análise de erros; Resolução de Problemas

Probabilidade; OBMEP; Análise de

(1)


ensino

aprendizagem.

\begin{tabular}{|c|c|c|c|}
\hline $\begin{array}{l}\text { Luís Carlos Góis } \\
\text { de Oliveira (2017) }\end{array}$ & $\begin{array}{l}\text { Análise de erros cometidos } \\
\text { pelos discentes do sétimo } \\
\text { ano do ensino fundamental } \\
\text { e primeiro ano do ensino } \\
\text { médio no estudo dos } \\
\text { números racionais na sua } \\
\text { forma fracionária }\end{array}$ & $\begin{array}{l}\text {. Universidade } \\
\text { Federal de Sergipe }\end{array}$ & $\begin{array}{l}\text { Frações; Análise de } \\
\text { erros: fundamental e } \\
\text { médio; Comparação } \\
\text { dos resultados. }\end{array}$ \\
\hline $\begin{array}{l}\text { Valdirene da Silva } \\
\text { de Sousa (2017) }\end{array}$ & $\begin{array}{l}\text { O erro no ensino de } \\
\text { Matemática: Reflexões a } \\
\text { respeito das ações docentes } \\
\text { no processo de ensino }\end{array}$ & $\begin{array}{l}\text { Pontifícia Universidade } \\
\text { Católica de São Paulo }\end{array}$ & $\begin{array}{lr}\text { Ensino } & \text { da } \\
\text { matemática. } & \text { Ensino } \\
\text { fundamental } & \text { I. erro. } \\
\text { Obstáculo } & \\
\end{array}$ \\
\hline $\begin{array}{l}\text { Tiago de Paula } \\
\text { Zagnoli (2017) }\end{array}$ & $\begin{array}{l}\text { Uma análise do erro de um } \\
\text { grupo de estudantes do } \\
\text { Ensino Médio em uma } \\
\text { escola de Juiz de Fora - } \\
\text { MG sob a ótica socio } \\
\text { contextual }\end{array}$ & $\begin{array}{l}\text { Universidade Federal de } \\
\text { Juiz de Fora }\end{array}$ & $\begin{array}{l}\text { Avaliação Escolar. } \\
\text { Erro. Produção } \\
\text { Escrita Matemática. } \\
\text { Desigualdade } \\
\text { Educacional. }\end{array}$ \\
\hline $\begin{array}{l}\text { Miriam Ferrazza } \\
\text { Heck (2017) }\end{array}$ & 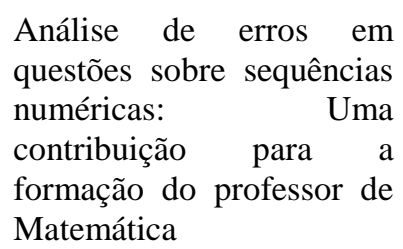 & $\begin{array}{ll}\text { Centro } & \text { Universitário } \\
\text { Franciscano } & \end{array}$ & $\begin{array}{lr}\text { Análise de erros. } \\
\text { Sequências } \\
\text { numéricas. Cursos de } \\
\text { formação } & \text { de } \\
\text { professores } & \text { de } \\
\text { Matemática } & \end{array}$ \\
\hline
\end{tabular}

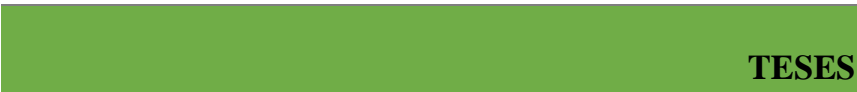

Autoria

Ano

Título da pesquisa

Instituição do ensino

Palavras-chaves

Maria Luisa

Perdigão Diz

Ramos (2014)
Dificuldades e erros de alunos do $1^{\circ}$ ano da educação profissional tecnológica de nível médio na modalidade integrada em matemática: reflexões e desafio
Dificuldade. Erro. Análise de erros. Universidade Cruzeiro do Funções. Ensino Sul Médio.
Objetos de aprendizagens multimodais e ensino de cálculo: Uma proposta baseada em análise de erros

Universidade Federal do Rio Grande do Sul Análise de erros. Objetos de aprendizagem.

Ambiente moodle

Cálculo. Educação

Messenas Miranda Rocha (2016)
Releitura do processo de aprendizagem de estudantes repetentes de Cálculo I
Universidade Federal do Matemática. Ensino Espírito Santo Superior. Funções de

Variáveis Reais.

Matemática

Emocional. 
Repetência

Educação.

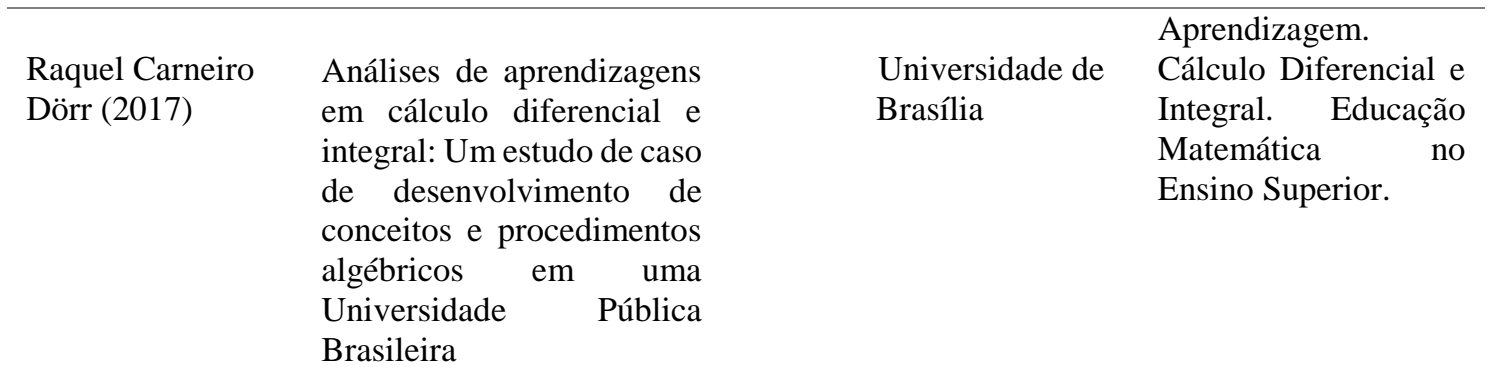

Fonte: elaborada pelos autores.

Distinguimos as distribuições das pesquisas segundo os níveis de ensino: fundamental, médio e superior respectivamente. Segundo o período de tempo considerando, o número das pesquisas sobre análise de erros é de 33\% para o ensino fundamental, 29\% para o ensino médio e 38\% correspondente ao ensino superior, e verificamos um aumento considerável dos temas relacionados com a análise de erros no ensino superior, o que pode ser visualizado no gráfico 1.

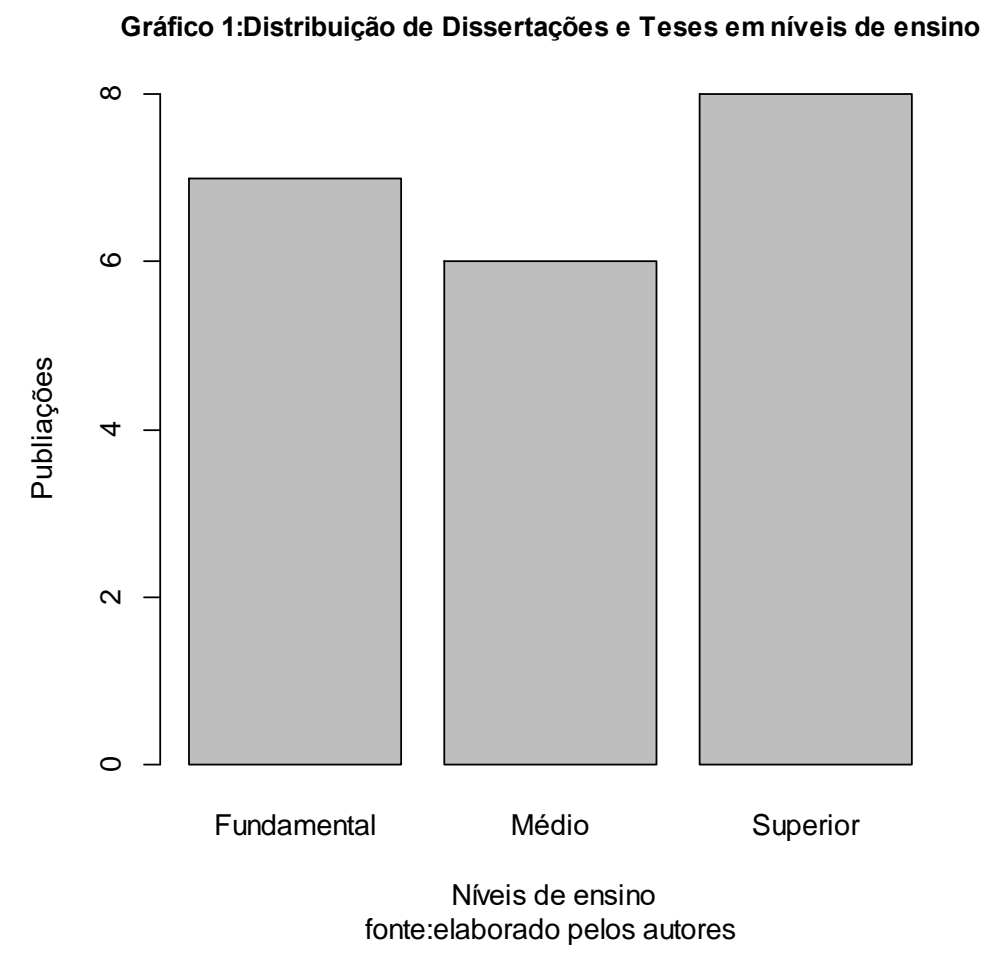

Revista REAMEC, Cuiabá (MT), v. 8, n. 3, p. 483-497, setembro-dezembro, 2020. 
Em relação aos temas abordados nas Dissertações e Teses, destaca-se, no período em estudo, uma maior concentração dos temas nos conteúdos de cálculo diferencial com uma percentagem de $28,57 \%$, o que pode ser visualizado no gráfico 2 com os demais temas.

\section{Gráfico 2: Distribuição dos temas nas Dissertações e Teses}

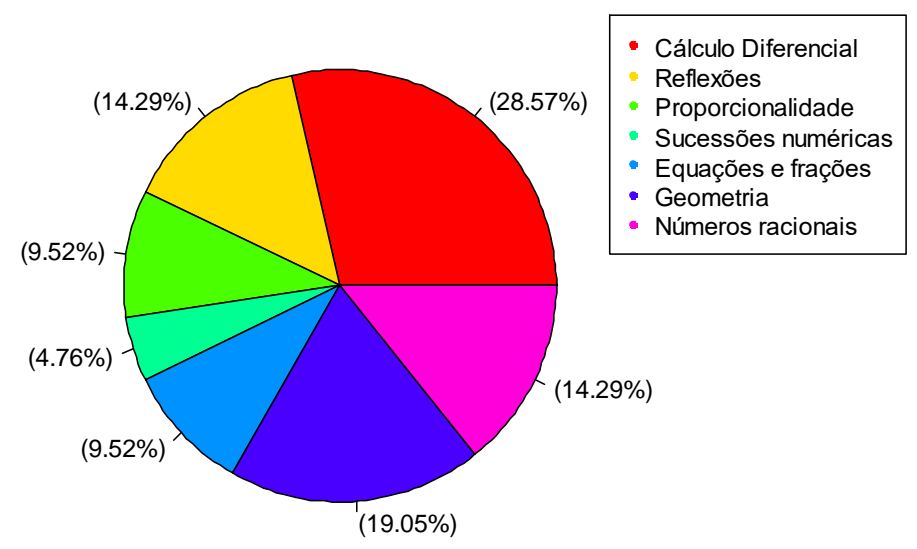

fonte:elaborado pelos autores

No mesmo período de 2014 a 2018, segundo as Dissertações e Teses levantadas, os dados indicam que houve uma maior produção nas Dissertações no ano de 2017 sobre o campo de pesquisa de análise de erros na Educação Matemática, contrariamente às Teses do doutorado que não obtemos muitas produções. De uma forma geral, verifica-se cada vez mais o interesse dos pesquisadores nesta área de análise de erros.

\subsection{Trabalhos selecionados para a leitura}

Neste campo, selecionamos alguns trabalhos para a leitura devido a aproximação com a nossa temática em estudo de Análise de erros em Cálculo I e do nível do ensino a ser pesquisado que é o ensino superior. Distinguimos cinco (5) Dissertações dos autores: Monção (2015), Santos (2015), Carvalho (2016), Nascimento (2017), Sousa (2017) e três (3) Teses dos autores: Müller (2015), Döor (2017) e Rocha (2016). A súmula dessas pesquisas conforme recomenda Creswell (2010) incluem: o problema da pesquisa, o foco do estudo, informações sobre a amostra, e os resultados fundamentais da pesquisa.

Monção (2015) dissertou sobre uma leitura dos erros cometidos por estudantes na resolução de questões do cálculo diferencial e integral, com o objetivo de diagnosticar os erros cometidos por 64 estudantes do curso de Zootecnia e Engenharia Agrônoma da Universidade 
Estadual de Montes Claros que tinham cursado a disciplina Cálculo I. Os resultados mostraram que o baixo desempenho dos estudantes nessa disciplina deve-se à deficiência de aprendizagem de conceitos matemáticos da Educação Básica (erros relacionados com soma algébrica, operações com frações, conceitos de função, potenciação, conceitos de trigonometria, produtos notáveis e erros em relação à ordem das operações a serem efetuadas), com maior ênfase na noção de função e nas operações com números reais, e erros ocorridos pela não apreensão de conceitos do Cálculo Diferencial e Integral (erros quanto à definições e teoremas referentes a limites, erros quanto às regras de derivação e erros devido à falta de domínio de conceitos de Integral).

Ao investigar a maneira como os professores interpretam os erros dos alunos de $4^{\circ} \mathrm{e}$ $5^{\circ}$ anos de ensino fundamental, em relação ao conteúdo envolvendo números racionais, foi aplicado um questionário para 312 professores dos quais 103 são do $4^{\circ}$ e 106 do $5^{\circ}$ ano e para 324 alunos distribuídos em sete (7) escolas públicas. O estudo constatou que os professores não interpretam satisfatoriamente os erros dos discentes devido às dificuldades dos próprios professores relativos ao conteúdo matemático e do conhecimento pedagógico que deveriam aplicar nas suas aulas (SANTOS, 2015).

Carvalho (2016) prelecionou acerca de análise de erros em Cálculo I como uma estratégia didática, com o objetivo de coletar e analisar os principais erros cometidos pelos alunos ingressantes no curso de Engenharia da Universidade Cândido Mendes, na disciplina de Cálculo I. A pesquisa foi desenvolvida com um grupo de 115 alunos, dos quais 60 do curso de Engenharia de Produção e 55 do curso de Engenharia Civil. Constatou-se que os erros dos alunos estão ligados a conceitos básicos da Matemática e que influenciam negativamente no aproveitamento pedagógico do cálculo I e noutras disciplinas. Recomendou-se o uso dos erros dos alunos como ferramentas para aumentar a eficiência do processo de ensino e aprendizagem da Matemática e as mudanças e abordagens do processo de ensino da disciplina de cálculo I.

Nascimento (2017) investigou a temática: Um estudo sobre os erros dos alunos em cálculo diferencial e integral I em um curso de engenharia civil, com o intuito de identificar os principais erros apresentados pelos alunos, do $2^{\circ}$ semestre do Curso de Engenharia Civil, na disciplina Cálculo Diferencial e Integral, especificamente os relacionados aos conteúdos de integrais. Tratou-se de um estudo de caso com uma turma de 40 alunos matriculados no $2^{\circ}$ semestre de Engenharia Civil de uma instituição de Ensino Superior Privada localizada no município de São Paulo. 
Os resultados mostraram que os alunos apresentam défice de compreensão de conteúdos de matemática básica, que acabam interferindo na compreensão e assimilação dos conteúdos da disciplina de Cálculo Diferencial e Integral. Os erros cometidos pelos alunos na resolução de exercícios estão relacionados com as operações básicas de matemática, propriedades das potências, divisão de frações, simplificação de frações e aplicação das regras de integração. Para a superação dos erros, a autora sugere aulas de nivelamento que não se preocupam somente na resolução de exercícios, mas, em uma metodologia diferenciada que promova uma discussão na sala em relação às dificuldades dos alunos, de modo, a perceber-se as causas dos erros e, que a avaliação não consista somente na publicação de conceitos, porém possa privilegiar também uma reflexão em relação aos erros cometidos.

Sousa (2017) dissertou sobre o erro no ensino de matemática: Reflexões a respeito de ações docentes no processo de ensino, com objetivo de investigar a forma os professores que ensinam matemática dos anos finais do ensino fundamental I se lidam com as situações em que os alunos apresentam erros nas suas atividades. A amostra foi composta de seis professores de $4^{\circ}$ ano e $5^{\circ}$ ano do Ensino Fundamental I, que lecionam em escolas de rede pública ou privada do município de São Paulo, tendo sido usada as entrevistas semiestruturadas para a coleta de dados. Os resultados indicaram que os professores raramente usam os erros na construção de conhecimentos de discentes nas suas aulas, alegando a insuficiência de tempo para essa tarefa. Os poucos que o fazem solicitam que os alunos apaguem as suas produções errôneas no quadro, substituindo por outras certas ou acabam copiando as resoluções corretas no quadro.

Müller (2015) pesquisou em sua tese de doutorado: Objetos de aprendizagens multimodais e ensino de cálculo: Uma proposta baseada em análise de erros, com o intuito de analisar as dificuldades de aprendizagem apresentadas por alunos de cálculo diferencial e integral e testar possibilidades de superar tais dificuldades, por meio de recursos tecnológicos e participaram 551 sujeitos na pesquisa. Os resultados mostraram que as maiores dificuldades dos estudantes se referiam a conteúdos de matemática básica, pré-requisitos para o cálculo, com mais ênfase na álgebra devido à má aplicação da propriedade distributiva da multiplicação sobre adição. Sugeriu o uso de recursos tecnológicos no laboratório para auxiliar os alunos a localizar e remediar as suas dificuldades, pois o uso da plataforma moodle mostrou maior desempenho aos estudantes nas atividades colocadas.

Rocha (2016) investigou em sua tese do doutorado a releitura do processo de aprendizagem de estudantes repetentes de Cálculo I, com o foco de analisar as respostas dos estudantes universitários repetentes da disciplina de Cálculo I em questões que envolvessem 
limites de funções reais a fim de levantar e refletir sobre os erros cometidos. O estudo iniciou com 38 alunos, devido às desistências dos estudantes, chegou-se na fase final com 26 alunos. Constatou-se dois tipos de erros de alunos que são: os referentes aos conteúdos da matemática básica (erros operatórios, quando o estudante tinha dificuldade de calcular o valor da função no ponto, errando operações com números reais, de simplificações e fatorações algébricas) e erros específicos do cálculo (na compreensão do conceito de limites laterais, na aplicação do conceito de unicidade do limite, de lapsos na escrita e no cálculo do limite de uma função a partir do gráfico da função). Para amenizar os erros e alcançar maior compreensão do limite de uma função, foi sugerido aos professores a inserção na rotina das aulas, as três formas de explicação sobre limites de funções (linguagem natural, representação geométrica e algébrica) e que possam considerar também nas suas aulas as experiências dos alunos.

Com o objetivo de analisar as produções escritas de estudantes de um curso inicial de Cálculo Diferencial e Integral e suas implicações no processo de aprendizagem no Ensino Superior; Döor (2017) conduziu uma pesquisa com estudantes de uma universidade pública do Centro-Oeste brasileiro. Constatou que uma parte considerável das dificuldades dos alunos está relacionada com os conceitos básicos de Matemática básica (operações com números e potências negativas, operações com valor absoluto, operações com frações, diferenciação entre as operações de multiplicação e potenciação, não distinção entre estruturas aditivas e multiplicativas) e dificuldades do simbolismo algébrico e com o uso da escrita matemática. Verificou também, a disposição de educadores matemáticos na criação de alternativas metodológicos que auxiliem os estudantes a superar suas dificuldades ao ingressarem na universidade, com a formação de aprendizagens sistematizados em diálogos pedagógicos e na mediação.

A partir das leituras das Dissertações e Teses selecionadas, podemos elucidar os aspectos seguintes:

- Os principais teóricos usados nessas pesquisas de análise de erros foram Cury (1995, 2004, 2007, 2007, 2008, 2013,); Pinto (2000); CORNU (1991); Torre (2007) e Luckesi (2008), Borasi (1996) e Peng \&Luo (2009), todavia nenhum dos trabalhos fez uma integração das concepções filosóficas de acordo como recomenda Creswell (2010);

- Monção (2015), Carvalho (2016), Nascimento (2017), Müller (2015), Rocha (2016) e Döor (2017) afirmam que os erros no cálculo diferencial e integral estão ligados aos conceitos de matemática básica; 
- Para além de erros, devido aos conteúdos da matemática básica, constatamos os específicos do Cálculo Diferencial e Integral relacionados com operações com os limites, propriedades de derivação e interação (MONÇÃO, 2015 e ROCHA, 2016);

- Santos (2015) e Sousa (2017) mostraram que os professores têm dificuldades para interpretarem os erros dos alunos;

- A coleta de dados nas Teses e Dissertações foi por meio de entrevistas e questionários e análise de dados foi embasada em análise de conteúdo de Bardin;

- Os pesquisadores propõem o uso dos erros conceituais como uma estratégia didática e que os professores possam melhorar as suas práticas de docência, considerando o erro como um fator relevante no processo de ensino - aprendizagem.

\section{CONSIDERAÇÕES FINAIS}

Esta pesquisa consistiu no levantamento de Dissertações e Teses sobre análise de erros na Educação Matemática, com mais ênfase na Análise de Erros em Cálculo Diferencial e Integral, no repositório de CAPES e dos programas de Pós-graduação das diversas regiões do Brasil.Verificou-se um aumento considerável de pesquisas sobre análise de erros conceituais com base nos dados levantados no período de 2014 a 2018, todavia, no ano de 2018, notou-se um decréscimo das pesquisas nesta área de conhecimento.

Os erros conceituais em Cálculo Diferencial e Integral estão mais relacionados com conteúdos da matemática básica e sugerimos o uso desses erros conceituais como oportunidades de aprendizagem e colocando os alunos como centro das aprendizagens, o que vai permitir que os erros sejam observáveis para eles.

Os erros conceituais, que não são oriundos de desatenção dos educandos, desempenham um papel preponderante no desenvolvimento científico, pois as aprendizagens sempre estão associadas às retificações de erros e servem como estratégias para os professores as potencializarem e que posteriormente reflitam sobre as suas práticas pedagógicas .

Apesar das pesquisadas revelarem défice no entendimento dos conteúdos da matemática básica por parte dos alunos, que acabam influenciando na ocorrência de erros no Cálculo Diferencial e Integral, recomendamos que as futuras pesquisas, além de apontarem os erros cometidos pelos alunos, seria também pertinente serem analisados como os documentos normativos que norteiam o ensino da Matemática, abordam a questão do erro e trazendo 
disscussões em relação às concepçoes dos professores em como detectar e interpretar os erros cometidos pelos alunos.

\section{REFERÊNCIAS}

BACHELARD, G (1884-1962). Formação do espírito científico: contribuição para uma psicanálise do conhecimento. Tradução Esteia dos Santos Abreu. - Rio de Janeiro: Contraponto, 1996.

CARVALHO, H, A. (2016). A análise dos erros dos alunos em Cálculo I como estratégia de ensino. 2016.75p. Dissertação (Mestrado profissional em Matemática) -Pontifícia Universidade Católica do Rio de Janeiro, Rio de Janeiro, 2016. Disponível em: https://sucupira.capes.gov.br/sucupira/public/consultas/coleta/trabalhoConclusao/viewTrabalh oConclusao.jsf?popup=true\&id_trabalho=5118135. Acesso em 19 de setembro de 2019.

CRESWELL, John W. Projeto de pesquisa: Métodos qualitativo, quantitativo e misto.3 eds. Porto Alegre: Artmed, 2010.

DÖRR, Raquel Carneiro. Análises de aprendizagens em cálculo diferencial e integral: um estudo de caso de desenvolvimento de conceitos e procedimentos algébricos em uma universidade pública brasileira. 2017. 237 f. Tese (Doutorado em Educação) - Universidade de, Brasília. 2017.Disponível em:

https://repositorio.unb.br/bitstream/10482/25283/1/2017_RaquelCarneiroD\%c3\%b6rr.pdf. Acesso em 15 de setembro de 2019.

HADAR, M, et al. (2005). An empirical classification model for errors in high school mathematics. Journal for Research in Mathematics Education. 18 (1), 3-14. Disponível em: https://www.researchgate.net/publication/263926481

An_Empirical_Classification_Model for_Errors_in_High_School_Mathematics. Acesso em 12 de abril de 2019.

MACEDO, L, D. Ensaios construtivistas.4. ed. São Paulo: Casa do Psicólogo,2002.

MONÇÃO, F, F. Uma leitura dos erros cometidos por estudantes na resolução de questões do cálculo diferencial e integral. 2015.Dissertação(Mestrado em Matemática) Universidade Estadual do Sudoeste da Bahia, 2015. Disponível em:

https://sucupira.capes.gov.br/sucupira/public/consultas/coleta/trabalhoConclusao/viewTrabalh oConclusao.jsf?popup=true\&id_trabalho=2524213. Acesso em 31de dezembro de 2019.

MÜLLER, T, J. Objetos de aprendizagem Multimodais e Ensino de Cálculo: Uma proposta baseada em análise de erros. 2015.203f. Tese (Doutora em Informática na Educação) - Universidade Federal do Grande do Sul, 2015. Disponível em: https://sucupira.capes.gov.br/sucupira/public/consultas/coleta/trabalhoConclusao/viewTrabalh oConclusao.jsf?popup=true\&id trabalho=2666279. Acesso em 15 de setembro de 2019.

NASCIMENTO, Patrícia Cacho. Estudo sobre os Erros dos alunos em Cálculo Diferencial e Integral I em curso de engenharia civil .2017.91 f. Dissertação (Mestrado 
Académico em Ensino de ciências e Matemática) - Universidade Cruzeiro do Sul, São Paulo ,2017. Disponível em:

https://sucupira.capes.gov.br/sucupira/public/consultas/coleta/trabalhoConclusao/viewTrabalh oConclusao.jsf?popup=true\&id trabalho=6089251. Acesso em 15 de setembro de 2019.

PINTO, N, B. O erro como estratégia didática: Estudo do erro no ensino da matemática elementar, campinas, SP: Papirus, 2000.

POPPER, Karl (1902-1994). Conjeturas e refutações. Lisboa Edições 70, 2018.

RICO, Luis, et al. Educação Matemática: Errores y dificultades de los estudiantes Resolución de problemas Evaluación Historia. Bogotá, 1998. Disponível em:

https://www.researchgate.net/publication/278009025_Educacion_Matematica_Errores_y_difi cultades_de_los_estudiantes_Resolucion_de_problemas_Evaluacion_Historia. Acesso em 11 de dezembro de 2019.

ROCHA, Messenas, Miranda. Releitura do Processo de Aprendizagem de Estudantes Repetentes de Cálculo I .2016.247f. Tese (Doutoramento em Educação) - Centro de Educação, Universidade Federal do Espírito Santo. Vitória -ES ,2016. Disponível em: https://sucupira.capes.gov.br/sucupira/public/consultas/coleta/trabalhoConclusao/viewTrabalh oConclusao.jsf?popup=true\&id_trabalho=4067445. Acesso em 12 de novembro de 2019.

ROMANOWSKI, J, R e ENS, R, T. As pesquisas denominadas do tipo "estado da arte" em Educação. Diálogo Educ., Curitiba, v. 6, n.19, p.37-50, set./dez. 2006. Disponível em: https://www.redalyc.org/pdf/1891/189116275004.pdf. Acesso em 15 de abril de 2019.

SOUSA, Valdirene da Silva de. O erro no ensino de Matemática: Reflexões a respeito de ações docentes no processo de ensino.2017. 130f.Dissertação(Mestrado em Educação Matemática) - Pontifícia Universidade Católica de São Paulo, São Paulo, 2017.Disponível em https://sucupira.capes.gov.br/sucupira/public/consultas/coleta/trabalhoConclusao/viewTrabalh oConclusao.jsf?popup=true\&id_trabalho=5436995. Acesso em 12 de novembro de 2019.

Submetido em: 10 de março de 2020.

Aprovado em: 07 de setembro de 2020. 